\title{
The Study of Optical and Electrical Properties of Nanostructured Silicon Carbide Thin Films Grown by Pulsed-Laser Deposition
}

\author{
Muhanad A. Ahmed ${ }^{1}$, Mohammed M. Sabri², Wathiq R. Abed ${ }^{1}$ \\ ${ }^{1}$ Department of Electrical Techniques, Institute of Technology, Middle Technical University, \\ Baghdad, Iraq \\ ${ }^{2}$ Department of Physics, Faculty of Science and Health, Koya University Koya KOY45, \\ Kurdistan Region - F.R. Iraq
}

\begin{abstract}
In this paper, nanostructured silicon carbide ( $\mathrm{SiC}$ ) thin films are deposited onto glass substrate using pulsed laser deposition technique. Electrical and optical characterizations such as conductivity, resistivity, transmission, Seeback effect, absorption, absorption coefficient, energy band gap, and extinction coefficient as a function of photon energy, and the effect of thin films thickness on transmission are carried out to characterize the prepared samples. Results showed that the prepared $\mathrm{SiC}$ thin film is an n-type semiconductor with an indirect bandgap of $\sim 3 \mathrm{eV}$, $448 \mathrm{~nm}$ cutoff wavelength, $3.4395 \times 10^{4} \mathrm{~cm}^{-1}$ absorption coefficient and 0.154 extinction coefficient. The surface morphology of the $\mathrm{SiC}$ thin films is studied using scanning electron microscope at a substrate temperature of $400^{\circ} \mathrm{C}$ and it is found that the grain size of the prepared $\mathrm{SiC}$ thin film is about $30 \mathrm{~nm}$. As such, the nano thin films optical and structural characteristics enable the films to be used as gases sensors in many optoelectronic devices such as the environment and ultraviolet photodiode.
\end{abstract}

Index Terms-Nanostructure, Pulsed laser deposition, Silicon carbide, Thin film.

\section{INTRODUCTION}

Due to their potential application in many forms of optoelectronic devices such as photodiodes, image sensors and solar cells, crystalline silicon carbide ( $\mathrm{SiC}$ ) thin films have attracted a considerable attention in recent years (Jha and Agarwal, 2015; Phan, et al., 2015 and Xu, et al., 2020). Pulsed-laser deposition (PLD) (Ahmed, Sabri and Mohammad, 2020) is now an established technique for the production of a wide range of thin films (Zakaria, et al., 2020 and Wang, et al., 2021). High quality ceramic films can be

ARO-The Scientific Journal of Koya University

Vol. IX, No.2 (2021), Article ID: ARO.10852, 5 pages

DOI: $10.14500 /$ aro. 10852

Received: 09 August 2021; Accepted: 18 October 2021

Regular research paper; Published: 10 November 2021

Corresponding author's email: muhanad.adil@mtu.edu.iq

Copyright (C) 2021 Muhanad A. Ahmed, Mohammed M. Sabri,

Wathiq R. Abed. This is an open-access article distributed under the

Creative Commons Attribution License. produced by PLD technique at much lower temperatures compared to that produced by other techniques. Nowadays, Radio Frequency (RF) sputtering technique and NeodymiumDoped Yttrium Aluminum Garnet (Nd-YAQ) laser typically perform films screened by PLD (Gupta, Sauer and Tsui, 2013). The energy from the photons depends on the type of the gas mixture used to create the Nd-YAG. For instance, when Nd-YAG is used, photons of energy 4-eV are released. PLD technique is performed in a high-vacuum atmosphere and the synthesized film and target material have the similar stoichiometric ratio, which can realize the growth of multilayer film and superlattice on the atomic level clean interface in the similar cavity, with a huge application range, easy control, quick growth rate, and adjustable deposition parameter (Chen, et al., 2009). Recently, PLD has been widely used for the fabrication of various technological devices photovoltaic cells and light emitting diodes (Ogugua, Ntwaeaborwa and Swart, 2020). In addition, PLD films have applied as protective barriers in corrosive atmosphere. All these applications made PLD a unique technique for growing complex and multi-component ceramic thin films.

$\mathrm{SiC}$ is an IV-IV compound material with unique physical and chemical properties. The strong chemical bonding between $\mathrm{Si}$ and $\mathrm{C}$ atoms gives this material high hardness, chemical inertness, and high thermal conductivity (Kimoto and Cooper, 2014). As a semiconductor, $\mathrm{SiC}$ exhibits a wide band gap $(2.2 \mathrm{eV}-3.2 \mathrm{eV})$, high breakdown field $\left(>20 \times 10^{5} \mathrm{~V} \mathrm{~cm}^{-1}\right)$, good thermal conductivity $\left(5 \mathrm{~W} \mathrm{~cm}^{-1} \mathrm{~K}^{-1}-7 \mathrm{~W} \mathrm{~cm}^{-1} \mathrm{~K}^{-1}\right)$, and high mobility $\left(10^{3} \mathrm{~cm}^{2} / \mathrm{Vs}\right)$. Among the various types of $\mathrm{SiC}$, cubic $\mathrm{SiC}$ (3C-SiC) has a crystal structure of great interest for piezoresistive applications such as pressure sensors (Dao, et al., 2016), advanced bioelectronic devices (Saddow et al., 2014), electrochemical applications (Yang and Jiang, 2019), and photovoltaic applications (Rasheed, et al., 2020). $\mathrm{SiC}$ provides a variety of optical and electronic applications (Majidi, et al., 2018 and Abderrazak and Hmida, 2011). All the above-mentioned properties and applications make $\mathrm{SiC}$ a promising material for manufacturing of high temperature, high frequency, and high-power devices (Liu, Tuttlr and Dhar, 2015 and Ho, et al., 2012). The electrical engineering sector 
including high voltage requirements could therefore be able to replace $\mathrm{Si}$ power transistors, thermistors, and rectifiers with $\mathrm{SiC}$ devices in the future (Rabkowski, Peftitsis and Nee, 2012). SiC crystal growth has then been undergone several progresses to contribute in industrial wafers and epitaxial structures (Kimoto, 2016). Furthermore, the optimum performance of microwave systems is related to ohmic contact accuracy, low contact strength, and a high temperature stability (Phan, et al., 2017). In addition, the interest of SiC and its various types have rapidly increased including various applications in optoelectronic devices and electronic such as semiconductors lasers, solar cells, modulators, and detectors, which mainly operates under high frequency, high temperature conditions, high power, and intensive radiation. Simple $\alpha-\mathrm{SiC}$ is an endogenous semiconductor with an energy band gap of $2.2 \mathrm{eV}$ to render it an extremely poor electrical conductor $\left(\sim 10 \Omega^{-1} \cdot \mathrm{cm}^{-1}-13 \quad \Omega^{-1} \cdot \mathrm{cm}^{-1}\right)$. These together with its chemical and mechanical stability accounts for its extensive use during the heating elements of electricity. Furthermore, a high temperature semiconductor such as pure $\beta$-SiC (band gap $=3.3 \mathrm{eV}$ ) has different applications in electro-luminescent diodes, diode rectifiers, transistors, and also in the future nuclear systems (Li, et al., 2018 and Aristov, 2001).

The main objective of this work is synthesizing $\mathrm{SiC}$ thin film by the usage of PLD technique and then studying the important properties of this material.

\section{EXPeRIMENTAL Details}

It has been demonstrated that the PLD technique reproduces the target's stoichiometry. Herein, a $100 \mu \mathrm{m}$ sieve was sieved $5 \mathrm{~g}$ of $\beta$-SiC material. The high purity (99.999\%) $\mathrm{SiC}$ powder was pressed under 5 tons to obtain the targeted shape with a diameter of $2.5 \mathrm{~cm}$ and a thickness of $0.4 \mathrm{~cm}$. The aim should be as dense and homogeneous as possible to ensure a good deposit quality and be used to deposit a thin SiC film on a glass slide. The glass slides that used as substrates have the area of $3 \times 2 \mathrm{~cm}^{2}$. To remove impurities and residuals from their surfaces, the glass slides were cleaned using alcohol with ultrasonic waves generated by Cerry PUL for $15 \mathrm{~min}$. The Nd-YAG laser wavelength was at $532 \mathrm{~nm}$ and with pulse width of $7 \mathrm{~ns}$ and operates at up to $10 \mathrm{~Hz}$.

The laser beam at a fluence of $1.5 \mathrm{~J} / \mathrm{cm}^{2}$ was centered on a high purity $\mathrm{SiC}$ target. The substrates were located $6 \mathrm{~cm}$ away from the $\mathrm{SiC}$ target. A diffusion pump was used, and the chamber was held at a vacuum pressure of $10^{-6}$ torr. To achieve single layer thin films, the $\mathrm{SiC}$ target was ablated from 10 to 100 pulses in $10 \mathrm{~min}-20 \mathrm{~min}$. The substrate temperatures (Ts) were preserved at $400^{\circ} \mathrm{C}$ during the deposition process. The following measurements were then included transmission and absorption spectrum, type of conductivity $(\sigma)$ and resistivity $(\rho)$ as functions of temperature, absorption coefficient $(\alpha)$ as function of photon energy $(h v)$. In addition, the value and the nature of the energy band gap $\left(E_{g}\right)$ of the formed $\mathrm{SiC}$ structure, the extinction coefficient $\left(\mathrm{k}_{\mathrm{ex}}\right)$ at cutoff wavelength and the transmittance at different points at the inclined surface were also determined. Finally, the thickness and the morphology of the film were estimated from the cross-sectional scanning electron microscopy (SEM) of type SEM JEOL 7000.

\section{ReSUlts AND Discussion}

Fig. 1 shows the transmission spectrum of the $\mathrm{SiC}$ thin film in the range of 300-900 nm wavelengths. Three distinguished regions are observed from this figure. First, in the ultraviolet (UV) range, the transmittance increases rapidly from 53.1\% to about $80 \%$ within the range of $300-400 \mathrm{~nm}$ wavelengths, indicating that $\mathrm{SiC}$ thin film absorbs the UV wavelength well and the maximum absorption is included. In the second region, within the visible range $(400 \mathrm{~nm}-700 \mathrm{~nm})$, the transmittance is increasing slowly from $80 \%$ to $92.5 \%$ and the cutoff wavelength is included in this range. Hence, the absorption is mainly determined by the thickness of the $\mathrm{SiC}$ film according to Beer-Lambert law (Axelevitch, Gorenstein and Golan, 2012). Finally, and beyond $700 \mathrm{~nm}$, the absorption is at the minimum and the $\mathrm{SiC}$ film is approximately transparent to the infrared (IR) wavelengths and this gives such films to be used as optical windows.

Fig. 2 shows the results of Seeback measurements, which confirm that the $\mathrm{SiC}$ film is n-type semiconductor. As can be seen from this figure, Seebeck voltage develops continuously with increasing the temperature until reaching a certain value at which this voltage remains constant (this is noticed at about $-18 \mathrm{~V}$ in Fig. 2) due to the stability of electrical properties related to the density of carriers and the dimensions of the sample. Few research works have also been published reporting the Seebeck coefficient-temperature relationship of silicon carbide such as in (Wang, et al., 2003 and Ohba, Shimozaki and Era, et al., 2008). Moreover, full details about Seebeck effect, Seebeck coefficient, and Seebeck voltage can be found in Molki, 2010, Iwanaga, et al., 2011 and Babaei, et al., 2017.

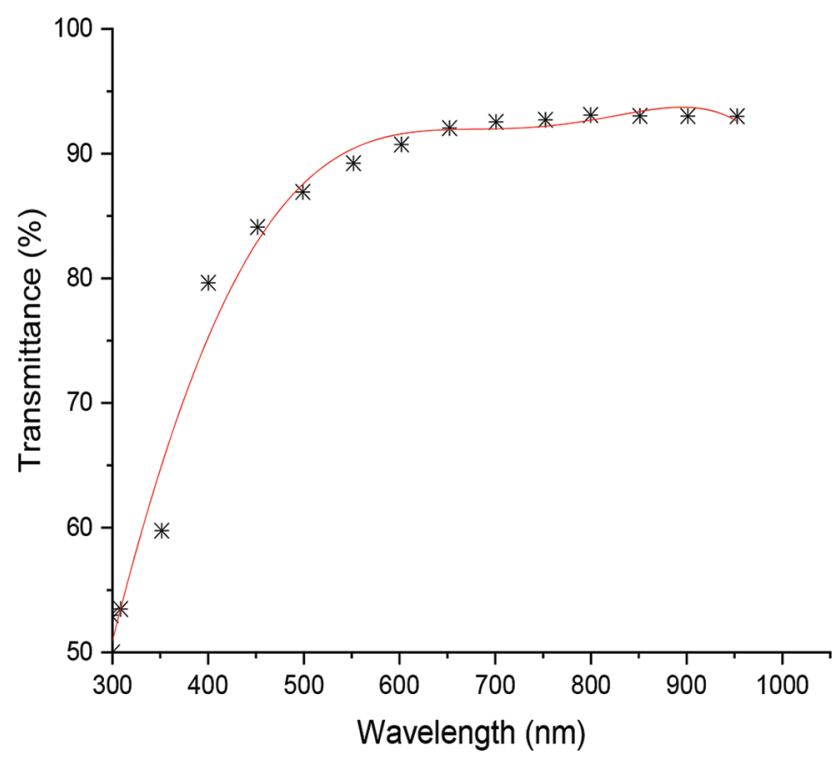

Fig. 1. Variation of silicon carbide thin film transmittance with the incident wavelength. The red line represents the fitting line. 


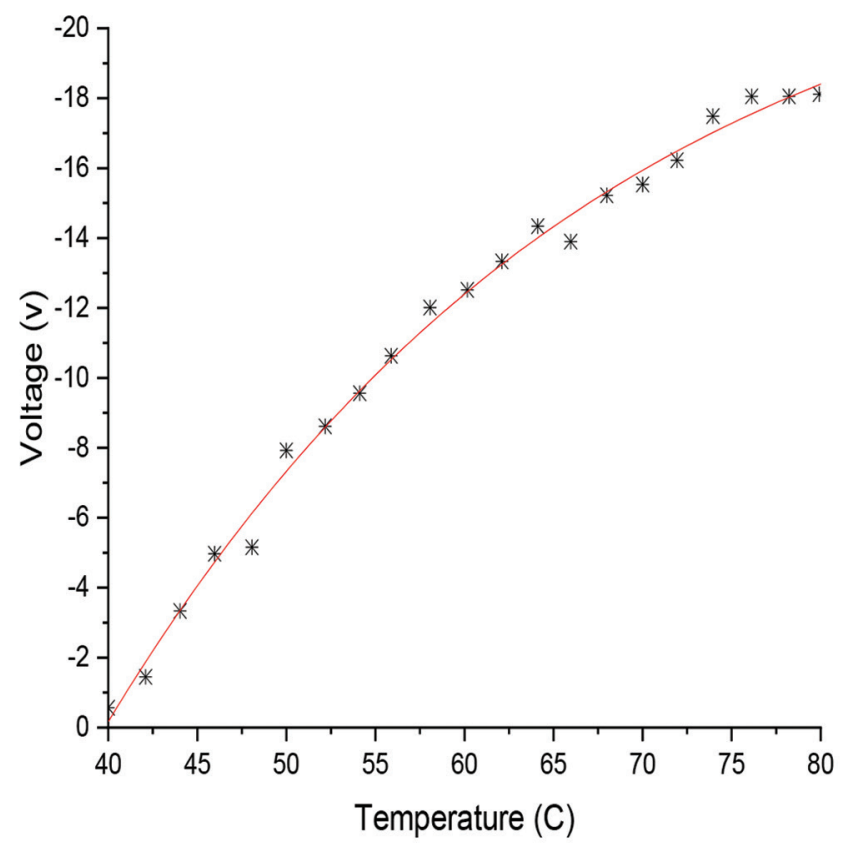

Fig. 2. Variation of Seebeck voltage with temperature. The red line represents the fitting line.

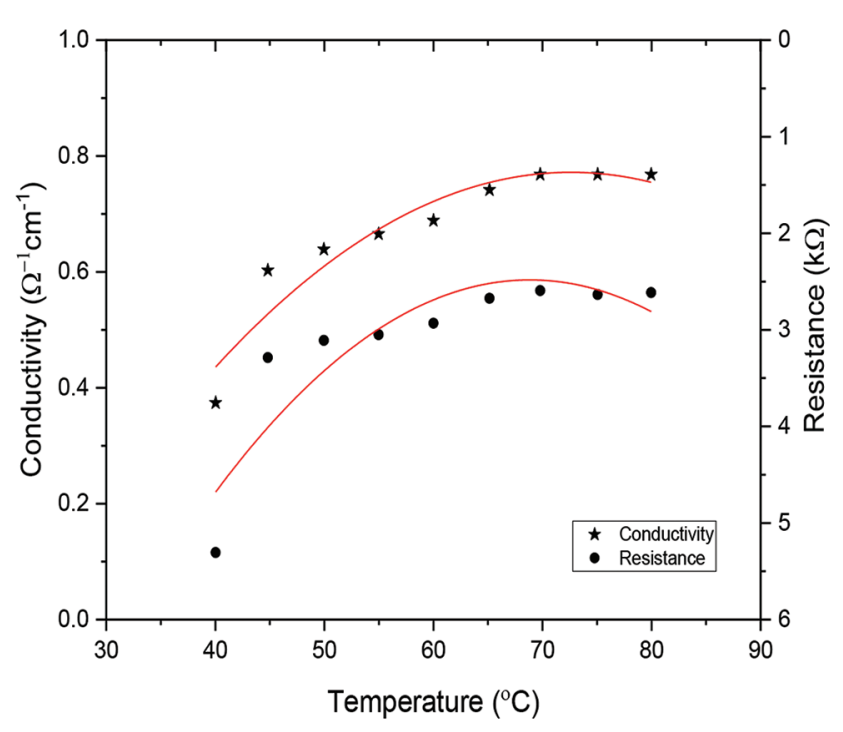

Fig. 3. Variation of the conductivity and resistance of silicon carbide thin film with temperature. The red line represents the fitting line.

Fig. 3 explains the variation of conductivity and resistance of the $\mathrm{SiC}$ thin film with temperature. Both properties are constant over the temperature of $70^{\circ} \mathrm{C}$. This is due to the fact that the prepared thin film is characterized by the steady properties at the elevated temperatures.

Fig. 4 represents the relation of absorption coefficient $(\alpha)$ with photon wavelength $(\lambda)$. The absorption coefficient drops rapidly within the range of $300 \mathrm{~nm}-600 \mathrm{~nm}$ assigning the minimum at about $448 \mathrm{~nm}$ which represents the cutoff wavelength $\left(\lambda_{\text {cutoff }}\right)$.

Fig. 5, on the other hand, shows the value of the energy bandgap $\left(E_{g}\right)$ of the $\mathrm{SiC}$ thin film, which is about $3 \mathrm{eV}$. Absorption processes $\left(\alpha^{2}\right)$ was graphed versus photon energy

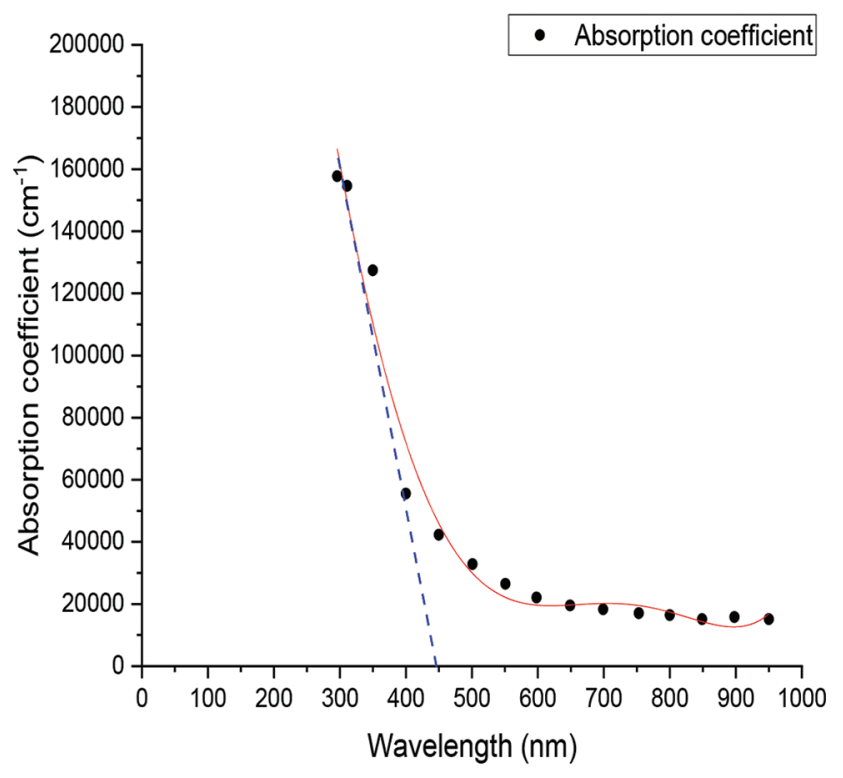

Fig. 4. Variation of absorption coefficient with the wavelength of the incident photon of silicon carbide thin film. The cutoff wavelength is $448 \mathrm{~nm}$. The red line represents the fitting line.

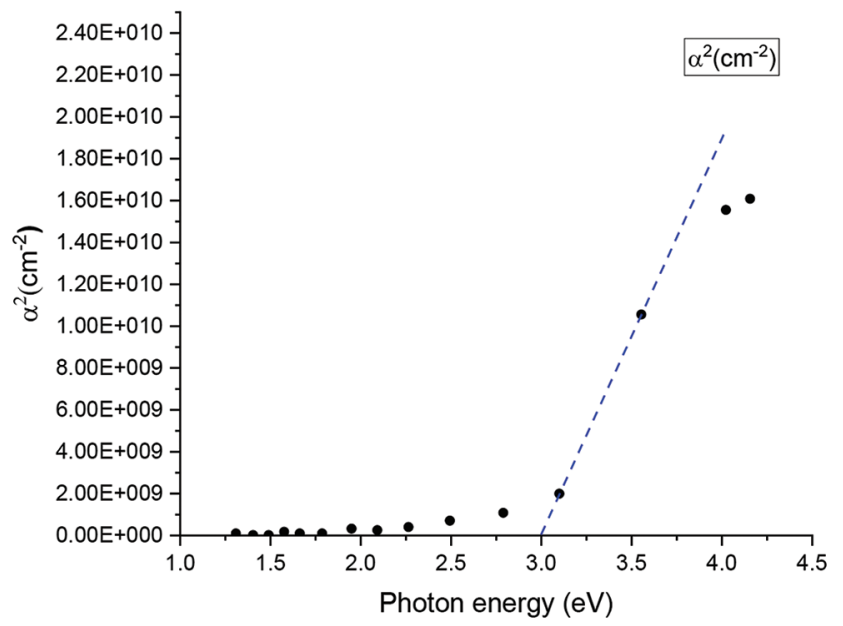

Fig. 5. Variation of $\alpha^{2}$ with the incident photon energy of the silicon carbide thin film. The energy gap is about $3 \mathrm{eV}$.

$(h v)$. Consequently, the $\mathrm{SiC}$ thin film that prepared in this work has an indirect band-gap and the allowed fundamental absorption processes are the dominant.

Furthermore, the extinction coefficient $\left(\mathrm{k}_{\mathrm{ex}}\right)$ is represented in Fig. 6 as a function of photon energy.

The typical value of $\mathrm{k}_{\mathrm{ex}}$ at minimum absorption $(448 \mathrm{~nm})$ is around 0.154 (the black arrow in Fig. 6). Due to the inclination of the thin film deposition, the transmittance is supposed to change with the film thickness (The deposited film had a thickness of approximately $50 \mathrm{~nm}$ ) on the inclined surface. Since we did not measure the film thickness at each point on the inclined surface, we measured the transmittance as the function of the incident wavelength then determine the relative transmittance at four different points on the inclined surface. Fig. 7 shows the decrease in transmittance as the 


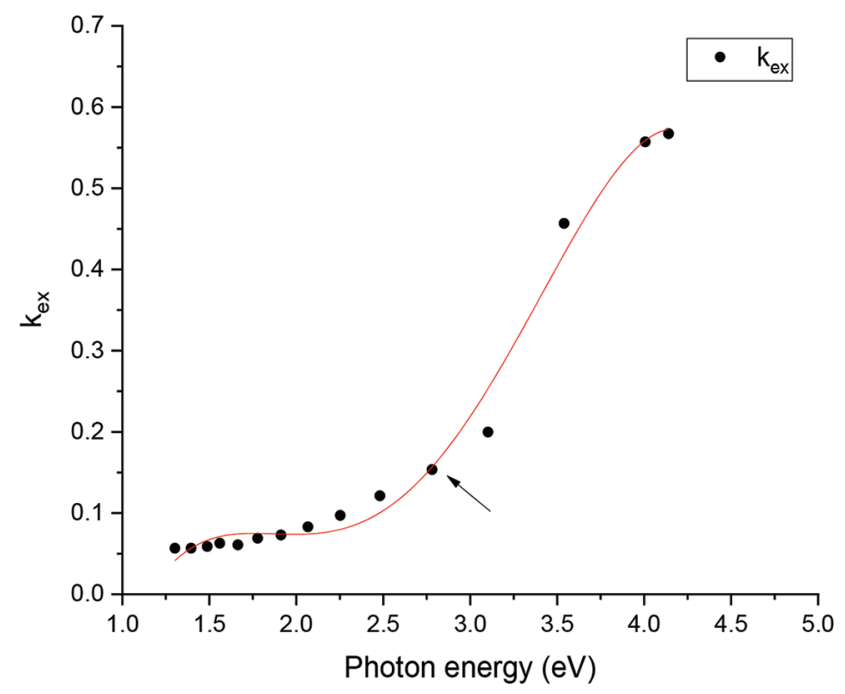

Fig. 6. Variation of the extinction coefficient $\left(\mathrm{k}_{\mathrm{ex}}\right)$ with the incident photon energy. The red line represents the fitting line.

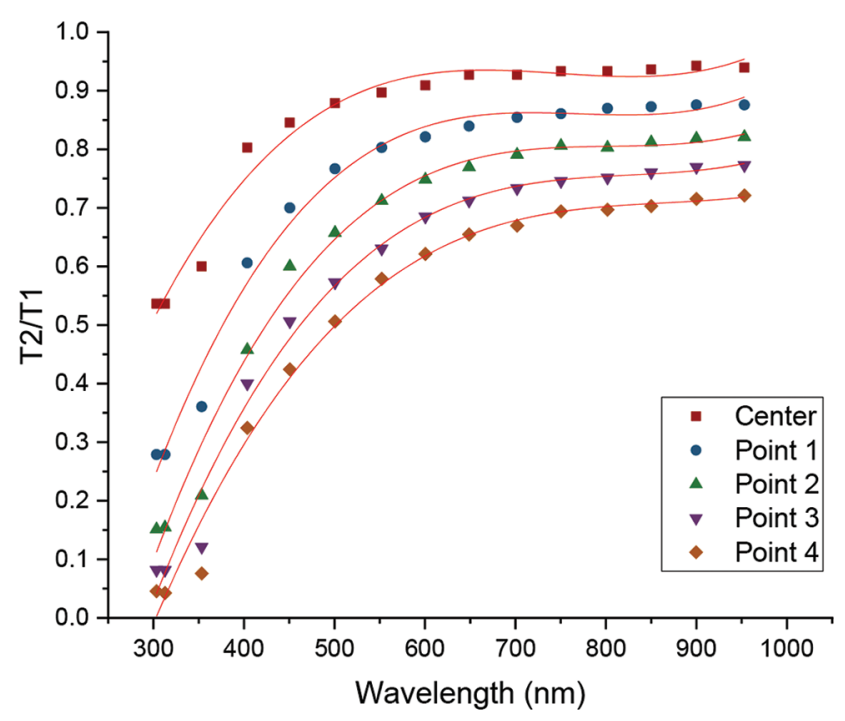

Fig. 7. Variation of the transmittance at center and different points on the inclined deposited thin films. The red lines represent the fitting lines.

thickness is increasing on the inclined surface. The first top line in Fig. 7 represents the center point followed by the other four points.

The thickness at each point at a certain wavelength can roughly be determined as follows:

$$
\begin{gathered}
I_{1}=I_{0} \exp \left(-a d_{1}\right)----(1 a) \text { at thickness } d_{1} \\
I_{1}=I_{0} \exp \left(-a d_{P}\right)----(1 b) \text { at thickness } d_{P}=u d_{1}
\end{gathered}
$$

where $u$ is the multiple of thickness at different point ( $p$ ) than the center $\left(\mathrm{d}_{1}=50 \mathrm{~nm}\right)$. Then:

$$
U=\frac{\ln T_{P}}{\ln T}
$$

where $\mathrm{Tp}$ and $\mathrm{T}$ are the transmittance at point $\mathrm{p}$ and the transmittance at the minimum thickness $(50 \mathrm{~nm})$,

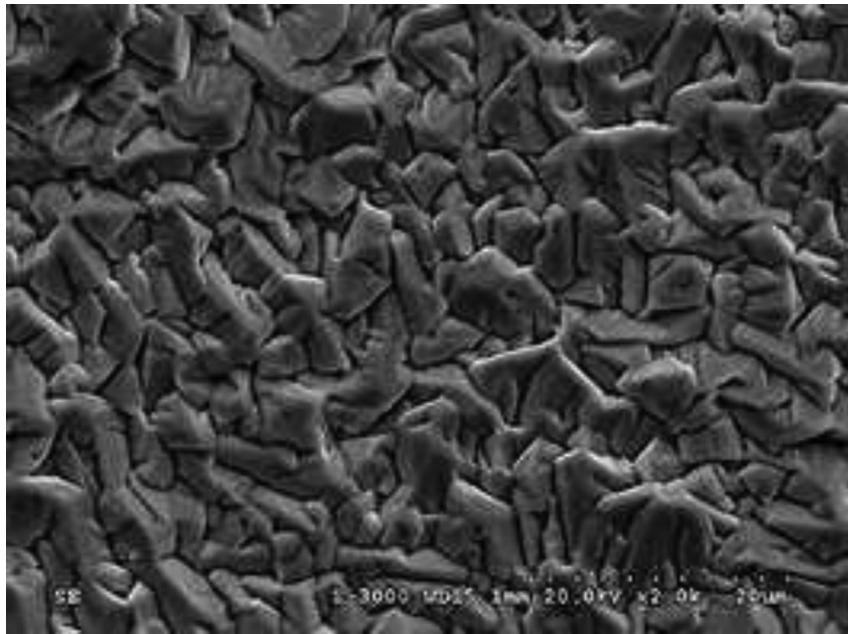

Fig. 8. Scanning electron microscopy micrograph of silicon carbide nanostructure thin film at substrate temperature of $400^{\circ} \mathrm{C}$.

respectively. Hence, as transmittance decrease to about $4 \%$ at the last point (point 4), then we predict that the thickness at this point is 5 times thicker than that at the center.

Fig. 8 shows the SEM image of the SiC thin films prepared at a substrate temperature of $400^{\circ} \mathrm{C}$. This image shows that the $\mathrm{SiC}$ nanoparticle was obtained in an agglomerated state and also the voids were occurred between the grains of the $\mathrm{SiC}$ thin films, which have a quite uniform and hole-free surface. The film has homogeneous surface morphology, with a grain size of about $30 \mathrm{~nm}$ and most particles are polyhedron-shaped with some facets.

\section{CONCLUSIONS}

Nanostructured deposits of $\mathrm{SiC}$ were prepared in vacuum on glass substrates by nanosecond PLD at operating wavelength of $532 \mathrm{~nm}$. Based on the obtained results, the deposited $\mathrm{SiC}$ films are of a high-transparent at visible and IR wavelengths, the electrical conductivity is of n-type and being constant at temperatures over $70^{\circ} \mathrm{C}$, the experimental measured values included cut-off wavelength of $448 \mathrm{~nm}$, the energy bandgap is indirect and of about $3 \mathrm{eV}$, the absorption coefficient of about $3.4395 \times 10^{4} \mathrm{~cm}^{-1}$ and the extinction coefficient of 0.154 . The transmittance of such structure could be controlled by the thickness along the inclined surface, which is, in turn, a function of the substrate inclination angle. The surface morphology of the deposits $\mathrm{SiC}$ thin films has been studied using SEM and it was found that the film has homogeneous surface morphology with a grain size of about $30 \mathrm{~nm}$ at the Ts of $400^{\circ} \mathrm{C}$. Such films are of a considerable impact in hightemperatures, high-power, and high-frequency applications. Therefore, this attempt may encourage to construct devices such as TFTs, detectors, solar cells, and optoelectronics.

\section{ACKNOWLEDGMENT}

Muhanad A. Ahmad expresses thanks and acknowledges to Oday Ata and Khalid Zakariya for their help during the experimental work. 


\section{REFERENCES}

Abderrazak, H. and Hmida E.S.B., 2011. Silicon carbide: Synthesis and properties. In: Gerhardt, R., (Ed.), Properties and Applications of Silicon Carbide. IntechOpen, London, United Kingdom. pp.361-388.

Ahmed, M.A., Sabri, M.M. and Mohammad, H.Q., 2020. Study of structural and optical properties of $\mathrm{Cu} 2 \mathrm{O}$ thin film prepared by rapid thermal annealing using Nd-YAG laser. NeuroQuantology, 18, pp.15-22.

Aristov, V.Y., 2001. $\beta$-SiC (100) surface: Atomic structures and electronic properties. Physics Uspekhi, 44, pp.761.

Axelevitch, A., Gorenstein, B. and Golan, G., 2012. Investigation of optical transmission in thin metal films. Physics Procedia, 32, pp.1-13.

Babaei, F.H., Faramarz, Masoumi, S. and Noori, A., 2017. Seebeck voltage measurement in undoped metal oxide semiconductors. Measurement Science and Technology, 28, p.115002.

Chen, B., Yang, D., Charpentier, P.A. and Zeman, M., 2009. Al ${ }^{3+}$-doped vanadium dioxide thin films deposited by PLD. Solar Energy Materials and Solar Cells, 93, pp.1550-1554.

Dao, D.V., Phan, H.P., Qamar, A. and Dinh, T., 2016. Piezoresistive effect of p-type single crystalline 3C-SiC on (111) plane. Royal Society of Chemistry (RSC) Advances, 6, pp.21302-21307.

Gupta, M., Sauer, V. and Tsui, Y.Y., 2013. Pulsed laser deposition of uniform semiconductor nanodot arrays. Applied Physics A, 110, pp.817-821.

Ho, C.N.M., Breuninger, H., Pettersson, S., Excobar, G., Serpa, L.A. and Coccia, A., 2012. Practical design and implementation procedure of an interleaved boost convertor using $\mathrm{SiC}$ diodes for PV applications. IEEE Transactions on Power Electronics, 27, pp.2835-2845.

Iwanaga, S., Toberer, E.S., LaLonde, A. and Snyder, G.J., 2011. A high temperature apparatus for measurement of the Seebeck coefficient. Review of Scientific Instruments, 82, pp.063905-063906.

Jha, H.S. and Agarwal, P., 2015. Highly crystalline silicon carbide thin films grown at low substrate temperature by HWCVD technique. Journal of Materials Science: Materials in Electronics, 26, pp.1381-1388.

Kimoto, T. and Cooper, J.A., 2014. Fundamentals of Silicon Carbide Technology: Growth, Characterization, Devices and Applications. John Wiley and Sons, New York, United States. pp.1-544.

Kimoto, T., 2016. Bulk and epitaxial growth of silicon carbide. Progress in Crystal Growth and Characterization of Materials, 62, pp.329-351.

Li, M., Zhou, X., Yang, H., Du, S. and Huang, Q., 2018. The critical issues of $\mathrm{SiC}$ materials for future nuclear systems. Scripta Materialia, 143, pp.149-153.

Liu, G., Tuttlr, B.R. and Dhar, S., 2015. Silicon carbide: A unique platform for metal-oxide-semiconductor physics. Applied Physics Reviews, 2, p.021307.

Majidi, S., Nezafat, N.B., Rai, D.P., Achour, A., Ghaziasadi, H., Sheykhian, A. and Solaymani, S., 2018. Optical and electronic properties of pure and fully hydrogenated $\mathrm{SiC}$ and $\mathrm{GeC}$ nanosheets: First-principles study. Optical and Quantum Electronics, 50, p.292.
Molki, A., 2010. Simple demonstration of the Seebeck effect. Science Education Review, 9, pp.103-107.

Ogugua, S.N., Ntwaeaborwa, O.M. and Swart, H.C., 2020. Latest development on pulsed laser deposited thin films for advanced luminescence applications. Coatings, 10, pp.1078-1100.

Ohba, Y., Shimozaki, T. and Era, H., 2008. Thermoelectric properties of silicon carbide sintered with addition of boron carbide, carbon, and alumina. Materials Transactions, 49, pp.1235-1241.

Phan, H.P., Cheng, H.H., Dinh, T., Wood, B., Nguyen, T.K., Mu, F., Kamble, H., Vadivelu, R., Walker, G., Hold, L., Iacopi, A., Haylock, B., Dao, D.V., Lobino, M., Suga, T. and Nguyen, N-T., 2017. Single-crystalline 3C-SiC anodically bonded onto glass: An excellent platform for high-temperature electronics and bioapplications. American Chemical Society (ACS) Applied Materials and Interfaces, 9, pp.27365-27371.

Phan, H.P., Dao, D.V., Wang, L., Dinh, T., Nguyen, N.T., Qamar, A., Tanner, P., Dimitrijev, S. and Zhu, Y., 2015. Strain effect on electrical conductance of P-type nanocrystalline silicon carbide thin film. Journal of Materials Chemistry C, 3, pp.1172-1176.

Rabkowski, J., Peftitsis, D. and Nee, H.P., 2012. Silicon carbide power transistors: Anew era in power electronics is initiated. IEEE Industrial Electronics Magazine, 6, pp.17-26.

Rasheed, M.N., Maryam, A., Fatima, K., Iqbal, F., Afzal, M., Syvajarvi, M., Murtaza, H., Zhu, B. and Asghar, M., 2020. Enhanced electrical properties on nonstructural cubic silicon carbide with graphene contact for photovoltaic applications. Digest Journal of Nanomaterials and Biostructures, 15, pp.963-972.

Saddowa, S.E., Frewina, C.L., Reyesa, M., Registera, J., Nezafatia, M. and Thomasa, S., 2014. 3C-SiC on Si: A biocompatible material for advanced bioelectronic devices. ECS Transactions, 61, pp.101-111.

Wang, D., Yang, Y., Guo, T., Xiong, X., Xie, Y., Li, K., Li, B. and Ghali, M., 2021. Effect of pulse bias voltages on performance of CdTe thin film solar cells prepared by pulsed laser deposition. Solar Energy, 213, pp.118-125.

Wang, X.H., Yamamoto, A., Eguchi, K., Obara, H. and Yoshida, T., 2003. Thermoelectric properties of SiC thick films deposited by thermal plasma physical vapor deposition. Science and Technology of Advanced Materials, 4, pp.167-172.

Xu, Z., Tao, K., Jiang, S., Jia, R., Li, W., Zhou, Y., Jin, Z. and Liu, X., 2020. Application of polycrystalline silicon carbide thin films as the passivating contacts for silicon solar cells. Solar Energy Materials and Solar Cells, 206, p.110329.

Yang, N. and Jiang, X., 2019. Cubic silicon carbide: Growth, properties, and electrochemical applications. In: Novel Carbon Materials and Composites. Wiely, Hoboken, New Jersey, pp.1-33.

Zakaria, M.A., Menazea, A.A., Mostafa, A.M. and Al-Ashkar, E.A., 2020. Ultrathin silver nanoparticles film prepared via pulsed laser deposition: Synthesis, characterization, and its catalytic activity on reduction of 4-nitrophenol. Surfaces and Interfaces, 19, p.100438. 